\title{
Construction of different structures of 4-Regular Planar Graph with odd region and even region
}

\author{
Dr Atowar ul Islam, Dr Samarjit Das
}

\begin{abstract}
In this present work we have discussed the construction of a structure of the 4-regular planar graphs for $\mathrm{G}(2 \mathrm{~m}+2,4 \mathrm{~m}+4)$ where $\mathrm{m} \geq 2$. Based on our proposed structure we have stated one theorem on odd regions of 4-regular planar graphs. The experimental results and proof of the stated theorems have also been provided.
\end{abstract}

Keywords: 4-Regular planar graphs, sub-graphs, structure, odd regions, total regions.

\section{INTRODUCTION}

Various researchers have been working on Regular planar graphs from different perspective. A Michael et al [1] have discussed an infinite class of connected 4-regular planar graphs which are not 3-connected and do not admit a realization as a system of circles. Shon Moo Young [2 ] have proposed that the regular planar graphs with diameter two are classified. Dutta Anupam et al. [3] have discussed regular planar sub graphs of complete graphs and their various application. The minimum vertex cover of a class of regular planar sub-graphs $\mathrm{H}(2 \mathrm{~m}+2,3 \mathrm{~m}+3), \mathrm{K}(2 \mathrm{~m}+2,4 \mathrm{~m}+4)$ for $\mathrm{m} \geq 2$ and $\mathrm{J}(2 \mathrm{~m}+2,5 \mathrm{~m}+5)$ for $\mathrm{m} \geq 5$ obtained from the complete graph $\mathrm{K} 2 \mathrm{~m}+2$ had already been discussed by Kalita et.al [4]. They have developed an algorithm to find the minimum vertex cover of these types of regular planar sub-graphs. They have also provided the application of the same on minimum vertex cover to reduce the power consumption of sensor network. Kalita et al[5] have discussed the construction of the structures of three regular planner graphs from the graph $G(2 m+2,3 m+3)$ for $m \geq 2$. They have studied its numbers of even and odd regions. They have also developed an algorithm and provided an application of it in region based. Ackerman Eyal et al [6] have proved that if an n-vertex graph $\mathrm{G}$ can be drawn in the plane such that each pair of crossing edges is independent and there is a crossing-free edge that connects their endpoints, then $G$ has $\mathrm{O}(\mathrm{n})$ edges. Graphs that admit such drawings are related to quasi-planar graphs and to maximal 1-planar and fan-planar graphs. Yu Yong et al [7] have proved that planar graph $G$ with maximum degree $\Delta \geq 12$ that the $(2,1)$-total

\footnotetext{
Manuscript revised September 19, 2019 and published on September 28, 2019

First Author name, His Department Name, University/ College/ Organization Name, City Name, Country Name.

Second Author name, His Department Name, University/ Collegel Organization Name, City Name, Country Name.

Third Author name, His Department Name, University/ College/ Organization Name, City Name, Country Name
}

labeling number $\lambda_{2}(G)$ is at most $\Delta+2$. Hasheminezhad Mahdieh et al discussed that the 5-regular simple planar graphs can all be obtained from an elementary family of starting graphs by repeatedly applying a few local expansion operations. The proof uses an amalgam of theory and computation. By incorporating the recursion into the canonical construction path method of isomorph rejection, a generator of non-isomorphic embedded 5-regular planar graphs is obtained with time complexity $\mathrm{O}\left(\mathrm{n}^{2}\right)$ per isomorphism class.

In most of the literature, it is seen that almost all the works have been done on planar graph and regular planar graphs. Very few works are seen to be done on 3-regular planar graph and 4-regular planar graphs. But in the literature hardly any work is seen on odd region and even region of 4-regular planar graph. But the regions are used in different map coloring, image processing and biological diversity. Graph theory is used in biology and conservation efforts where a vertex represents regions where certain species exist and the edges represent migration path or movement between the regions. This information is important when looking at breeding patterns or tracking the spread of disease, parasites and to study the impact of migration that affects other species. Therefore, in the present work we propose two new theorems on the odd region and even region of 4 -regular planar graphs.

Section 1 includes the introduction which contains the works of another researcher. Section 2 includes the definition. Section 3 contains two theorems which are stated and proved. Section 4 includes discussion of odd region which covered by only three edges and Section 5 includes the conclusion.

\section{DEFINITION}

Region: An area covered by a number of vertices with edges is known as a region. A region is two types -inner region and outer region. The inner region are two types - odd region and even region.

Odd Region: If a region is covered by odd number of vertices and odd number of edges than it is called odd region. Example

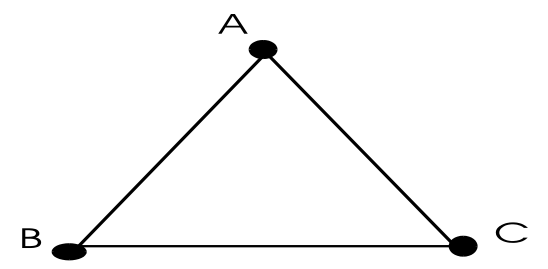

Figure 1: (bounded by odd number of edges)

Even Region: If a region covered by even number vertices and even number edges, called even region. Example- 


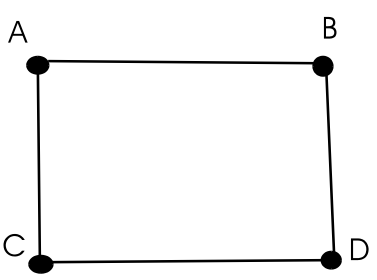

Figure 1: (bounded by Even number of edges)

Construction of Four Regular Planar Graphs: There are so many structure of 4 regular planar graphs. In this paper we focus only one type of structure for discussing the odd region and even region of the graph.

\section{OUR WORK}

For the graph $G(2 m+2,4 m+4)$ where $m \geq 2$, we construct the structures-1, structure-2 of Four-regular planar graphs in the following ways-

\section{Structure-1 :}

Let $G$ be a graph having $(2 m+2)$ vertices and $4(m+1)$ edges for $m \geq 2$.

For $\mathrm{m}=2, \mathrm{G}$ contains six vertices $\left\{\mathrm{v}_{1}, \mathrm{v}_{2}, \mathrm{v}_{3}, \mathrm{v}_{4}, \mathrm{v}_{5}, \mathrm{v}_{6}\right\}$ and twelve edges. Let us join these six vertices by twelve edges as follows:

$$
\propto\left(v_{\mathrm{i}}\right)=\left\{\begin{array}{l}
v_{\mathrm{i}+1} \text { for } 1 \leq i \leq 5 \\
v_{1} \text { for } i=3 \\
v_{4} \text { for } i=6
\end{array}\right.
$$

and $\propto\left(v_{\mathrm{j}}\right)=v_{\mathrm{j}+3}$ for $1 \leq j \leq 3$

and $\propto\left(v_{\mathrm{p}}\right)=v_{\mathrm{p}+4}$ for $1 \leq \mathrm{p} \leq 2$

Then we have the edge set $\left\{\mathrm{v}_{1} \mathrm{v}_{2}, \mathrm{v}_{2} \mathrm{v}_{3}, \mathrm{v}_{4} \mathrm{v}_{5}, \mathrm{v}_{5} \mathrm{v}_{6}, \mathrm{v}_{3} \mathrm{v}_{1}, \mathrm{v}\right.$ $\left.{ }_{6} \mathrm{~V}_{4}, \mathrm{~V}_{1} \mathrm{~V}_{4}, \mathrm{v}_{2} \mathrm{~V}_{5}, \mathrm{v}_{3} \mathrm{~V}_{6}, \mathrm{v}_{1} \mathrm{v}_{5}, \mathrm{v}_{2} \mathrm{v}_{6}, \mathrm{v}_{3} \mathrm{~V}_{4},\right\}$ and we obtain a graph [ Figure-3], which is planar and regular of degree four.

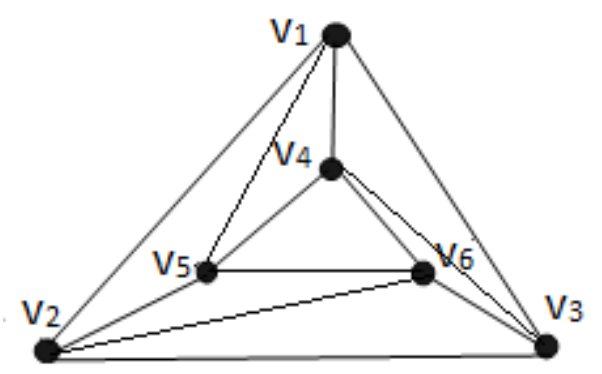

Figure 3: Four regular planar graph for $m=2$

From the above graph [Figure-3] we observed that it has seven odd regions (each bounded by three edges) and there is no any even edges.

For $\mathrm{m}=3$ vertex set is $\left\{\mathrm{v}_{1}, \mathrm{v}_{2}, \mathrm{v}_{3}, \mathrm{v}_{4}, \mathrm{v}_{5}, \mathrm{v}_{6}, \mathrm{v}_{7}, \mathrm{v}_{8}\right\}$ i.e eight vertices and sixteen edges. Let us join eight vertices with sixteen edges by the following rule.

$$
v_{5} \text { for } i=8
$$

and $\propto(v j)=v_{\mathrm{j}+4}$ for $1 \leq j \leq 4$

and $\propto(v \mathrm{p})=v_{\mathrm{p}+5}$ for $1 \leq j \leq 3$

Then we have the edge set $\left\{\mathrm{v}_{1} \mathrm{v}_{2}, \mathrm{v}_{2} \mathrm{v}_{3}, \mathrm{v}_{3} \mathrm{~V}_{4}, \mathrm{v}_{5} \mathrm{v}_{6}, \mathrm{v}_{6} \mathrm{~V}_{7}, \mathrm{v}_{7} \mathrm{v}_{8}, \mathrm{v}\right.$ $\left.{ }_{4} \mathrm{~V}_{1}, \mathrm{~V}_{8} \mathrm{~V}_{5}, \mathrm{~V}_{1} \mathrm{~V}_{5}, \mathrm{~V}_{2} \mathrm{~V}_{6}, \mathrm{~V}_{3} \mathrm{~V}_{7}, \mathrm{~V}_{4} \mathrm{~V}_{8}\right\}$ and we obtain a graph [Figure-4], which is planar and regular of degree three.

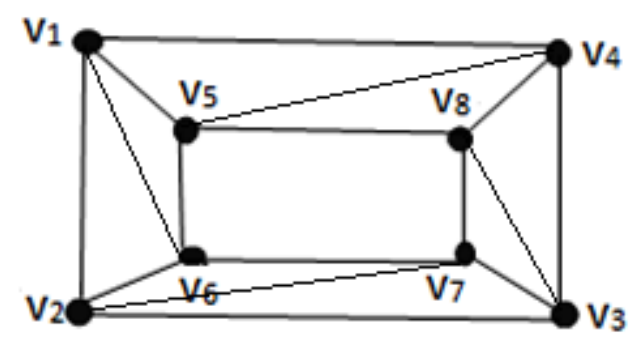

For $m=3$ vertex set is $\left\{\mathrm{v}_{1}, \mathrm{v}_{2}, \mathrm{v}_{3}, \mathrm{v}_{4}, \mathrm{v}_{5}, \mathrm{v}_{6}, \mathrm{v}_{7}, \mathrm{v}_{8}\right\}$ i.e eight vertices and sixteen edges. Let us join eight vertices with sixteen edges by the following rule.

$$
\propto\left(v_{\mathrm{i}}\right)=\left\{\begin{array}{l}
v_{\mathrm{i}+1} \text { for } 1 \leq i \leq 9 \\
v_{1} \text { for } i=5 \\
v_{6} \text { for } i=10
\end{array}\right.
$$

$$
\begin{aligned}
& \text { and } \propto(v j)=v_{\mathrm{j}+5} \text { for } 1 \leq j \leq 5 \\
& \text { and } \propto(v \mathrm{p})=v_{\mathrm{p}+6} \text { for } 1 \leq j \leq 4
\end{aligned}
$$

Then we have the edge set $\left\{\mathrm{v}_{1} \mathrm{v}_{2}, \mathrm{v}_{2} \mathrm{v}_{3}, \mathrm{v}_{3} \mathrm{v}_{4}, \mathrm{v}_{5} \mathrm{v}_{6}, \mathrm{v}_{6} \mathrm{v}_{7}, \mathrm{v}_{7} \mathrm{v}_{8}, \mathrm{v}\right.$ $\left.{ }_{4} \mathrm{~V}_{1}, \mathrm{~V}_{8} \mathrm{~V}_{5}, \mathrm{~V}_{1} \mathrm{~V}_{5}, \mathrm{~V}_{2} \mathrm{~V}_{6}, \mathrm{~V}_{3} \mathrm{~V}_{7}, \mathrm{~V}_{4} \mathrm{~V}_{8}\right\}$ and we obtain a graph [Figure-4], which is planar and regular of degree three.

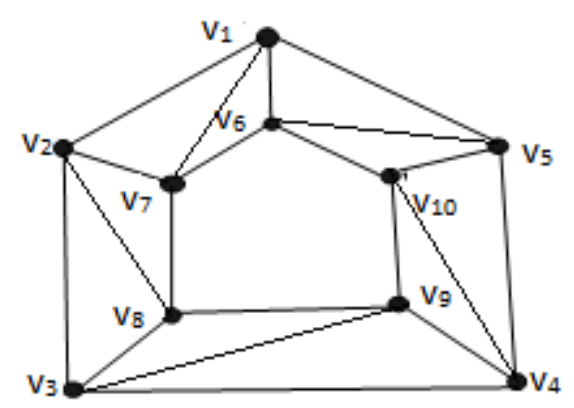

For $\mathrm{m}=3$ vertex set is $\left\{\mathrm{v}_{1}, \mathrm{v}_{2}, \mathrm{v}_{3}, \mathrm{v}_{4}, \mathrm{v}_{5}, \mathrm{v}_{6}, \mathrm{v}_{7}, \mathrm{v}_{8}\right\}$ i.e eight vertices and sixteen edges. Let us join eight vertices with sixteen edges by the following rule. 
and $\propto(v j)=v_{\mathrm{j}+6}$ for $1 \leq j \leq 6$

and $\propto(v \mathrm{p})=v_{\mathrm{p}+7}$ for $1 \leq j \leq 5$

Then we have the edge set $\left\{\mathrm{v}_{1} \mathrm{~V}_{2}, \mathrm{v}_{2} \mathrm{v}_{3}, \mathrm{~V}_{3} \mathrm{~V}_{4}, \mathrm{v}_{5} \mathrm{~V}_{6}, \mathrm{~V}_{6} \mathrm{~V}_{7}, \mathrm{v}_{7} \mathrm{~V}_{8}, \mathrm{~V}\right.$ $\left.{ }_{4} \mathrm{~V}_{1}, \mathrm{~V}_{8} \mathrm{~V}_{5}, \mathrm{~V}_{1} \mathrm{~V}_{5}, \mathrm{~V}_{2} \mathrm{~V}_{6}, \mathrm{~V}_{3} \mathrm{~V}{ }_{7}, \mathrm{~V}_{4} \mathrm{~V}_{8}\right\}$ and we obtain a graph [Figure-4], which is planar and regular of degree three.

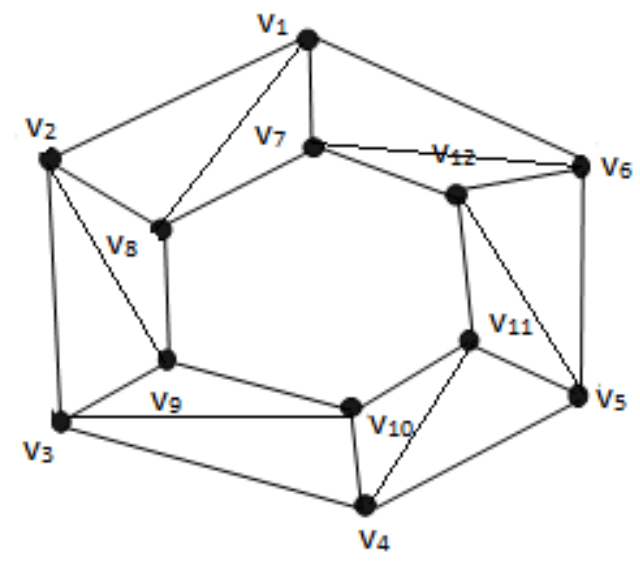

Similarly we can construct regular planar graph of degree three having odd and even regions for $m=6,7,8,9$----and hence we can generalize the above cases by the following rule for constructing the graph.

For the graph $\mathrm{G}$ having $2 \mathrm{~m}+2$ number of vertices and $3(\mathrm{~m}+1)$ edges for $m \geq 2$, we define

$\propto:: \mathrm{VG} \rightarrow \mathrm{VG}$ such that

$$
\propto\left(v_{\mathrm{i}}\right)=\left\{\begin{array}{l}
v_{i+1} \text { for } 1 \leq i \leq 2 m+1 \\
v_{1} \text { for } i=m+1 \\
v_{i-m} \text { for } i=2 m+2
\end{array}\right.
$$

and $\propto\left(v_{j}\right)=v_{j}+(m+1)$ for $1 \leq j \leq m+1$

and $\propto\left(v_{\mathrm{p}}\right)=v_{\mathrm{p}+(m+2)}$ for $1 \leq \mathrm{p} \leq m$

The experimental results of three regular planar graph $G(2 m+2,3 m+3)$ of structure- 1 for different values of $m \geq 2$ are shown in Table-1

\begin{tabular}{|l|l|l|l|l|l|l|}
\hline $\begin{array}{l}\text { Value } \\
\text { of } \mathrm{m}\end{array}$ & $\begin{array}{l}\text { Graph } \\
\text { (V,E) }\end{array}$ & $\begin{array}{l}\text { No } \\
\text { of } \\
\text { Odd } \\
\text { regi } \\
\text { on }\end{array}$ & $\begin{array}{l}\text { No of } \\
\text { Even } \\
\text { region }\end{array}$ & $\begin{array}{l}\text { Total } \\
\text { Region }\end{array}$ & $\begin{array}{l}\text { No of } \\
\text { Regions } \\
\text { covered } \\
\text { by three } \\
\text { edges }\end{array}$ & $\begin{array}{l}\text { No of } \\
\text { Regions } \\
\text { (odd or } \\
\text { even) } \\
\text { covered by } \\
\text { other than } \\
3 \text { edges }\end{array}$ \\
\hline 2 & 6,12 & 7 & NIL & 7 & 7 & 0 \\
\hline 3 & 8,16 & 8 & 1 & 9 & 8 & 1 \\
\hline 4 & 10,20 & 11 & 0 & 11 & 10 & 1 \\
\hline 5 & 12,24 & 12 & 1 & 13 & 12 & 1 \\
\hline 6 & 14,28 & 15 & 0 & 15 & 14 & 1 \\
\hline 7 & 16,32 & 16 & 1 & 17 & 16 & 1 \\
\hline
\end{tabular}

\begin{tabular}{|l|l|l|l|l|l|l|}
\hline 8 & 18,36 & 19 & 0 & 19 & 18 & 1 \\
\hline 9 & 20,40 & 20 & 1 & 21 & 20 & 1 \\
\hline 10 & 22,44 & 23 & 0 & 23 & 22 & 1 \\
\hline 11 & 24,48 & 24 & 1 & 25 & 24 & 1 \\
\hline 12 & 26,52 & 27 & 0 & 27 & 26 & 1 \\
\hline
\end{tabular}

From the following results we find a theorem.

Theorem1: The odd region of 4-Regular planar graph $\mathrm{G}(2 \mathrm{~m}+2,4 \mathrm{~m}+4)$ is $2 \mathrm{~m}+3$ when $\mathrm{m}=2 \mathrm{p}$ for $\mathrm{p} \geq 1$ and $2 \mathrm{~m}+2$ when $\mathrm{m}=2 \mathrm{p}+1$ for $\mathrm{p} \geq 1$.

Proof of the theorem by using mathematical induction:

Proof: It has been proved [3] that the sub-graph $\mathrm{H}(2 \mathrm{~m}+2,4 \mathrm{~m}+4)$ for of the complete graph $\mathrm{K}_{2 \mathrm{~m}+2}$ is planar and regular of the degree 4 . We now proceed to prove that the regular planar graph $\mathrm{H}(2 \mathrm{~m}+2,4 \mathrm{~m}+4)$ has odd region $2 \mathrm{~m}+3$ for $m=2 p$ and $2 m+2$ for $m=2 p+1$ for $p \geq 1$. It is found that the result is true when $m=2$ and 3 .That is, when $m=2$ for $p=1$, the graph $\mathrm{H}(6,12)$ has odd region 7 and the graph $\mathrm{H}(8,16)$ has odd region 8 when $\mathrm{m}=3$ for $\mathrm{p}=1$ which is shown from figure- 4 and figure-5.

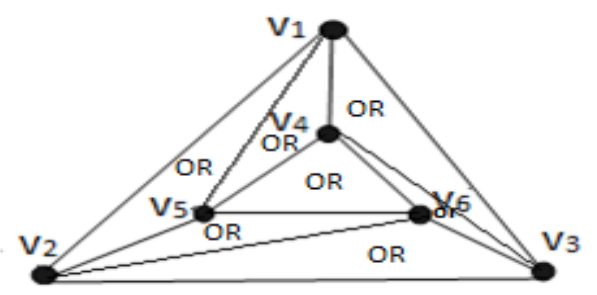

Fig-4:For $\mathrm{m}=2$ odd region is 7

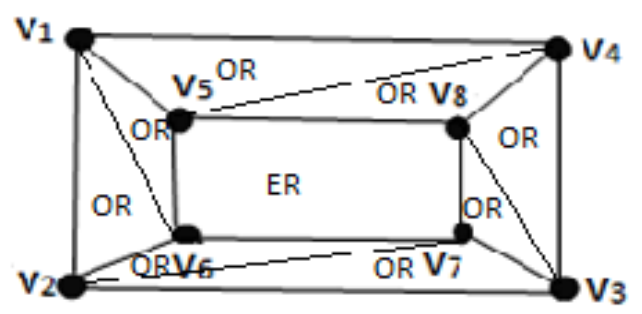

Fig -5 For $m=3$ odd region is 8

(For both Fig 4 and 5 OR means Odd Region)

The $1^{\text {st }}$ part of the theorem claims for the even value of $m$ is that if $m=2 p$ and $p>=1$ then Odd Region $O R(m)=2 m+3$ and the difference between the odd regions is always 4 for two consecutive values of $p$. 
Now, OR $(m)=2 m+3$

Therefore, when $\mathrm{p}=1,2$, we have $\mathrm{m}=2 \mathrm{p}$, So

$$
\begin{aligned}
& \mathrm{OR}_{\mathrm{p}=1}(2 \times 1=2)=\mathrm{OR}_{\mathrm{p}=1}(2)=2 \times 2+3=7 \\
& \mathrm{OR}_{\mathrm{p}=2}(2 \times 2=4)=\mathrm{OR}_{\mathrm{p}=2}(4)=2 \times 4+3=11 \\
& \mathrm{OR}_{\mathrm{p}=3}(2 \times 3=6)=\mathrm{OR}_{\mathrm{p}=3}(6)=2 \times 6+3=15
\end{aligned}
$$

Proceeding in the same manner, we get,

$$
\begin{aligned}
& \mathrm{OR}_{\mathrm{p}-1}(2(\mathrm{p}-1))=2(2 \mathrm{p}-2)+3=4 \mathrm{p}-1 \\
& \mathrm{OR}_{\mathrm{p}}(2 \mathrm{p})=2 \times 2 \mathrm{p}+3=4 \mathrm{p}+3
\end{aligned}
$$

From above results, the differences of the successive odd-regions is found as,

$$
\begin{gathered}
\mathrm{OR}_{\mathrm{p}=2}-\mathrm{OR}_{\mathrm{p}=1}=11-7=4 \\
\mathrm{OR}_{\mathrm{p}=3}-\mathrm{OR}_{\mathrm{p}=2}=15-11=4
\end{gathered}
$$

Proceeding in the same manner, we get,

$$
\begin{aligned}
\mathrm{OR}_{\mathrm{p}=\mathrm{p}}-\mathrm{OR}_{\mathrm{p}=\mathrm{p}-1}=(4 \mathrm{p}+3)-(4 \mathrm{p}-1) \\
\\
=4 \mathrm{p}+3-4 \mathrm{p}+1 \\
=4
\end{aligned}
$$

Hence the theorem is true for all $p \geq 1$ but had to prove for $p+1$ getting the generalization,

Now

Now

$$
\begin{aligned}
\mathrm{OR}_{\mathrm{p}=\mathrm{p}+1}(2 \times & (\mathrm{p}+1)=2(2 \mathrm{p}+2)+3 \\
& =4 \mathrm{p}+4+3 \\
& =4 \mathrm{p}+7
\end{aligned}
$$

$$
\begin{aligned}
\mathrm{OR}_{\mathrm{p}=\mathrm{p}+1}-\mathrm{OR}_{\mathrm{p}=\mathrm{p}}=(4 \mathrm{p}+7)-(4 \mathrm{p}+3) \\
\\
=4 \mathrm{p}+7-4 \mathrm{p}-3 \\
=4
\end{aligned}
$$

Since the theorem in true for $\mathrm{p}$ and and for $\mathrm{p}+1$ and it evidently proved true for $p=1,2,3$. Hence the $1^{\text {st }}$ part of theorem is true for any value of $\mathrm{p} \geq 1$.

The $2^{\text {nd }}$ part of the theorem claims for the odd value of $m$ is that if $m=2 p+1$ and $p>=1$ then Odd Region $O R(m)=2 m+2$ and the difference between the odd regions is always 4 for two consecutive values of $p$.

Now, $\operatorname{OR}(\mathrm{m})=2 \mathrm{~m}+2$

Therefore, when $p=1,2$, we have $m=2 p+1$, So

$$
\begin{aligned}
& \mathrm{OR}_{\mathrm{p}=1}(2 \times 1+1=3)=\mathrm{OR}_{\mathrm{p}=1}(3)=2 \times 3+2=8 \\
& \mathrm{OR}_{\mathrm{p}=2}(2 \times 2+1=5)=\mathrm{OR}_{\mathrm{p}=2}(5)=2 \times 5+2=12 \\
& \mathrm{OR}_{\mathrm{p}=3}(2 \times 3+1=7)=\mathrm{OR}_{\mathrm{p}=3}(7)=2 \times 7+2=16
\end{aligned}
$$

Proceeding in the same manner, we get,

$$
\begin{gathered}
\mathrm{OR}_{\mathrm{p}=\mathrm{p}-1}(2(\mathrm{p}-1)+1)=\mathrm{OR}_{\mathrm{p}=\mathrm{p}-1}(2 \mathrm{p}-1)=2(2 \mathrm{p}-1)+3 \\
=4 \mathrm{p}-2+3=4 \mathrm{p}+1 \\
\mathrm{OR}_{\mathrm{p}}(2 \mathrm{p}+1)=\mathrm{OR}_{\mathrm{p}=\mathrm{p}}(2 \mathrm{p}+1)=2(2 \mathrm{p}+1)+3=4 \mathrm{p}+2+3 \\
=4 \mathrm{p}+5
\end{gathered}
$$

From above results, the differences of the successive odd-regions is found as,

$$
\begin{aligned}
& \mathrm{OR}_{\mathrm{p}=2}-\mathrm{OR}_{\mathrm{p}=1}=12-8=4 \\
& \mathrm{OR}_{\mathrm{p}=3}-\mathrm{OR}_{\mathrm{p}=2}=16-12=4
\end{aligned}
$$

Proceeding in the same manner, we get,

$$
\begin{aligned}
\mathrm{OR}_{\mathrm{p}=\mathrm{p}}-\mathrm{OR}_{\mathrm{p}=\mathrm{p}-1} & =(4 \mathrm{p}+5)-(4 \mathrm{p}+1) \\
& =4 \mathrm{p}+5-4 \mathrm{p}-1 \\
& =4
\end{aligned}
$$

Hence the theorem is true for all $\mathrm{k} \geq 1$ but had to prove for $\mathrm{k}+1$ getting the generalization,
Now

Now

$$
\begin{aligned}
\mathrm{OR}_{\mathrm{p}=\mathrm{p}+1}(2 \times(\mathrm{p}+1)+1)=\mathrm{OR}_{\mathrm{p}=\mathrm{p}+1}(2 \mathrm{p}+3) & =2(2 \mathrm{p}+3)+3 \\
& =4 \mathrm{p}+6+3 \\
& =4 \mathrm{p}+9
\end{aligned}
$$

$$
\begin{aligned}
\mathrm{OR}_{\mathrm{p}=\mathrm{p}+1}-\mathrm{OR}_{\mathrm{p}=\mathrm{p}} & =(4 \mathrm{p}+9)-(4 \mathrm{p}+5) \\
& =4 \mathrm{p}+9-4 \mathrm{p}-5 \\
& =4
\end{aligned}
$$

Since the theorem in true for $\mathrm{k}$ and and for $\mathrm{k}+1$ and it evidently proved true for $\mathrm{k}=1,2,3$. Hence the $2^{\text {nd }}$ part of theorem is true for any value of $k \geq 1$.

\section{Discussion:}

Maximum Regions covered by three edges: The experimental results of structure of four regular planar graph $\mathrm{G}(2 \mathrm{~m}+2,4 \mathrm{~m}+4)$ for different values of $\mathrm{m} \geq 2$ are shown in Table-2. From the above table we observed that for $m=2$, sub-graph covered by 3 edges $=7$ and other region covered by more then 3 edges $=0$. Again for $m=3$, sub-graph covered by 3 edges $=8$ and other region covered by more then 3 edges $=1$. Again for $m=4$, sub-graph covered by 3 edges $=11$ and other regions are covered by more then 3 edges $=1$. Again for $m=5$, sub-graph covered by 3 edges $=12$ and other regions are covered by more then 3 edges $=1$.

From the above observation it is seen that the maximum region of the structure of the graph are covered by three edges and maximum other than three edges covered is only one.

From the above results, it is clear that the number of regions covered by the three edges change with the change of the values of ' $m$ ', let it be $f(x)$, and it is seen that number of other regions covered by other edges remain oscillated 1 irrespective the values of $\mathrm{m}$. Hence the total regions obtained by the edges will be $\mathrm{f}(\mathrm{x})+\mathrm{k}$, where $\mathrm{k}$ is 1 . But if the graph is very large and many edges are involved at that situation, the regions covered by the three edges will be distinctly high but $\mathrm{k}$ remains at 1 which can be neglected as it becomes so small as compared to the large value of $m$ and $f(x)$. so if we ignored the region which are covered by more than three edges then we can state that the structure of the graph $\mathrm{G}(2 \mathrm{~m}+2,4 \mathrm{~m}+4)$ region are covered by 3 edges.

\section{CONCluSION}

The above discussion is useful for the researchers of different fields like: mathematical science, region-based segmentation, biological diversity, region-based map coloring etc. , as the theorems discussed here justified our claims that the odd region of 4-Regular planar graph $\mathrm{G}(2 \mathrm{~m}+2,4 \mathrm{~m}+4)$ is $2 \mathrm{~m}+3$ when $m=2 p$ for $p \geq 1$ and $2 m+2$ when $m=2 p+1$ for $p \geq 1$.

\section{REFERENCES}

[1] Michael A. Bekos1 and Chrysanthi N. Raftopoulou “ Circle-Representations of Simple 4-Regular Planar Graphs, W. Didimo and M. Patrignani (Eds.): GD 2012, LNCS 7704, pp. 138-149, 2013. @ Springer-Verlag Berlin Heidelberg 2013. 


\section{Available online at www.ijrat.org}

[2] Moo Young SOHN Sang Bum KIM "Classification of Regular Planar Graphs with Diameter Two" Acta Mathematica Sinica, English Series Mar., 2007, Vol. 23, No. 3, pp. 411-416 Published online: Oct. 14, 2005, DOI: 10.1007/s10114-005-0607-4.

[3] Anupam Dutta, Bichitra Kalita and Hementa K.Baruah, "Regular Planar Sub- Graph of Complete Graph and their Application" International Journal of Applied Engineering Research ISSN 0973-4562 Volume 5 Number 3(2010) pp.377-386 @ research India Publication. Construction of a Structure from 4-Regular Planar Graph and to investigate its implications International organization of Scientific Research 38 | P a g e

[4] Atowar ul Islam, Bichitra Kalita and Anupam Dutta ," Minimum Vertex Cover of Different Regular Planar Graph and Its Application" International Journal of Mathematical Archive-5(10), 2014, 175-184 Available online through www.ijma.info ISSN 2229 -5046 .

[5] Atowar ul Islam, Jayanta Kr. Choudhury, Anupam Dutta and Bichitra Kalita , "Odd Region and Even Region of 3-Regular Planar Graph with its Application", Global Journal of Pure and Applied Mathematics. ISSN 0973-1768 Volume 13, Number 2 (2017), pp. 857-873 @ Research India Publications.

[6] Eyal Ackerman, Bal_azs Keszegh, Mate Vizer," On the size of planarly connected crossing graphs", Journal of Graph Algorithms

\section{AUTHORS PROFILE}

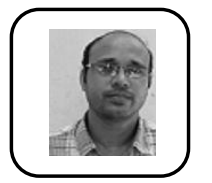

A.U. Islam completed his Masters in Computer Application from Dibrugarh University of Assam, India. He has obtained his Ph.D. in Computer Science and Engineering in 2018 from Gauhati University and currently working as Assistant Professor in Department of CSIT, Cotton University of Assam, India since 2008.

He has published multiple research papers in reputed international journals including Scopus and ACM Digital Indexing. His main research work focuses on Graph Theory. He has 11 years of teaching experience and 7 years of Research Experience.

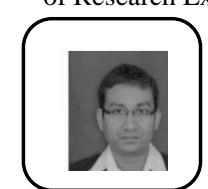

S Das completed his Masters in Mathematics from Gauhat University of Assam, India. He has obtained his Ph.D. in Computer Science and Engineering in 2017 from Gauhat University and currently working as Assistant Professor in Department of CSIT, Cotton University of Assam, India since 2008. He has published more than 10 research papers in reputed international journals. He has 43 citations of his research work. His main research work focuses on Pattern Recognition, Fuzzy Logic, Fuzzy Clustering, Data Mining, and Computational Mathematics based education. $\mathrm{He}$ has 15 years of teaching experience and 8 years of Research Experience. and Applications vol. 22, no. 1, pp. $11\{22$ (2018) DOI: 10.7155/jgaa.00453

[7] Young Yu,Xun Zhang, Gaunghui,Guizhen Liu, Jinbo Li, "(2,1)-total labelling of planar graphs with large maximum degree", Journal of mathematical Sciences and Cryptography, Pages 1625-1636 | Published online: 17 Jan 2018.

[8] Mahdieh Hasheminezhad 1 Brendan D. McKay 2 Tristan Reeves "Recursive generation of simple planar 5-regular graphs and pentangulations" Journal of Graph Algorithms and Applications, http://jgaa.info/ vol. 15, no. 3, pp. 417\{436 (2011) 